\title{
The search for the Holy Grail: Risk stratification in anomalous aortic origin of a coronary artery
}

\author{
Silvana Molossi, MD, PhD, ${ }^{\mathrm{a}, \mathrm{b}}$ and Carlos M. Mery, MD, $\mathrm{MPH}^{\mathrm{a}, \mathrm{c}}$
}

\footnotetext{
From the ${ }^{\mathrm{a} C}$ Coronary Anomalies Program, Texas Children's Hospital, Houston, Tex; and ${ }^{\mathrm{b}}$ The Lillie Frank Abercrombie Section of Pediatric Cardiology, and ${ }^{\mathrm{c} D i v i s i o n}$ of Congenital Heart Surgery, Department of Surgery, Texas Children's Hospital/Baylor College of Medicine, Houston, Tex.

Disclosures: Authors have nothing to disclose with regard to commercial support.

Received for publication Nov 20, 2017; accepted for publication Dec 4, 2017; available ahead of print Jan 6, 2018. Address for reprints: Carlos M. Mery, MD, MPH, Congenital Heart Surgery, Texas Children's Hospital, 6621 Fannin St MC19345H, Houston, TX 77030 (E-mail: cmmery@ texaschildrens.org).

J Thorac Cardiovasc Surg 2018;155:1758-9

$0022-5223 / \$ 36.00$

Copyright (c) 2017 by The American Association for Thoracic Surgery

https://doi.org/10.1016/j.jtcvs.2017.12.026
}

Sudden cardiac death continues to shatter families and communities at large, despite its rarity. Anomalous aortic origin of a coronary artery (AAOCA) from the opposite sinus of Valsalva, the second most common cause of sudden cardiac death in young patients, ${ }^{1}$ claims young lives every year. Despite a wealth of information on anatomic types, course, degree of stenosis on dynamic assessment, advanced imaging (Figure 1), and evaluation of myocardial ischemia, ${ }^{2,3}$ we remain devoid of defined measures to stratify those at risk.

In this issue of the Journal, Sachdeva and colleagues ${ }^{4}$ report a single-center experience with the unroofing procedure in AAOCA during a 17-year period. One of the salient and disturbing findings of this series was that 3 patients suffered a sudden cardiac arrest (SCA) 2-6 years after the unroofing procedure, 2 of whom had an initial presentation of SCA. Given the retrospective nature of the study and the heterogeneity of preoperative and postoperative anatomic and functional imaging, the reasons for these occurrences are unknown. However, they highlight one of the inherent limitations of our counseling of families on surgical intervention (or not) for AAOCA. Does surgical intervention alter the risk of SCA in a particular patient? Were all anatomic culprits addressed in these patients at the time of surgery or was the unroofing procedure incomplete or inadequate? Does presenting with SCA translate into a greater risk for a recurrent event? Do patients presenting with SCA have myocardial scarring that predisposes them to recurrent SCA despite surgical intervention? Should we place automated internal cardiac defibrillators in those presenting with SCA? What tests can we use to risk-stratify patients?

These are just a few of many unanswered questions in AAOCA. We recently described a basketball player who had an unroofing procedure for an anomalous left coronary artery after SCA but presented with a recurrent episode of SCA 20 months later. ${ }^{5}$ Postoperative stress cardiac magnetic resonance imaging had shown no perfusion abnormalities and no scarring, but further imaging showed

\section{References}

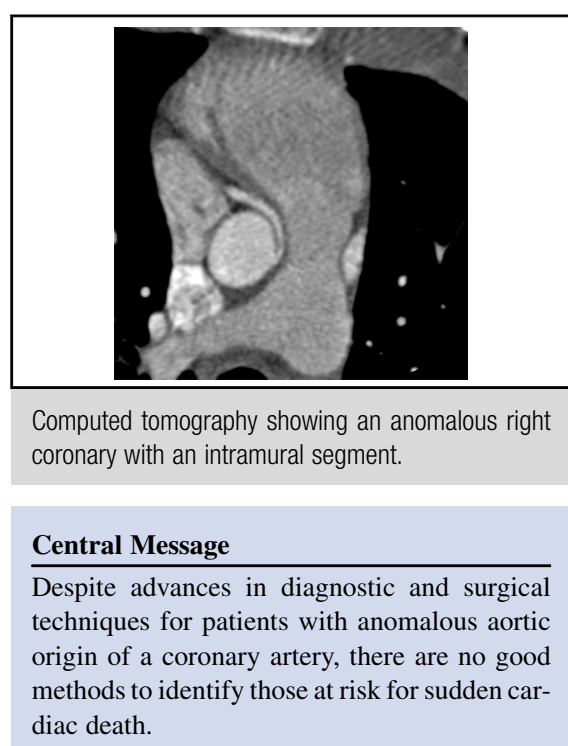

See Article page 1760 .

residual narrowing of the left coronary artery due to a procedure that failed to address compression of the vessel by the intercoronary pillar.

Although meaningful information is provided by this surgical series, ${ }^{4}$ there are inherent limitations that are common to similar retrospective series of AAOCA without standardized management, namely, short and incomplete follow-up, the lack of a true denominator (all patients with AAOCA regardless of whether they had surgery or not), inconsistent preoperative and postoperative evaluation, and the inclusion of patients with other significant congenital heart diseases and impaired ventricular function.

Unquestionably, this study urges the scientific community to unite in acquiring consistent prospective long-term data on these patients through efforts such as the Congenital Heart Surgeons' Society Registry on AAOCA, ${ }^{6}$ standardization of workup within each center, ${ }^{7}$ and multi-institutional collaboration for development of consistent approaches on imaging, functional assessment, and longitudinal follow-up. We may not see the blossomed fruits of these efforts in our lifetime, but we ought to be planting the seeds for our children and grandchildren to benefit in the future.

1. Maron BJ, Doerer JJ, Haas TS, Tierney DM, Mueller FO. Sudden deaths in young competitive athletes: analysis of 1866 deaths in the United States, 1980-2006. Circulation. 2009;119:1085-92. 

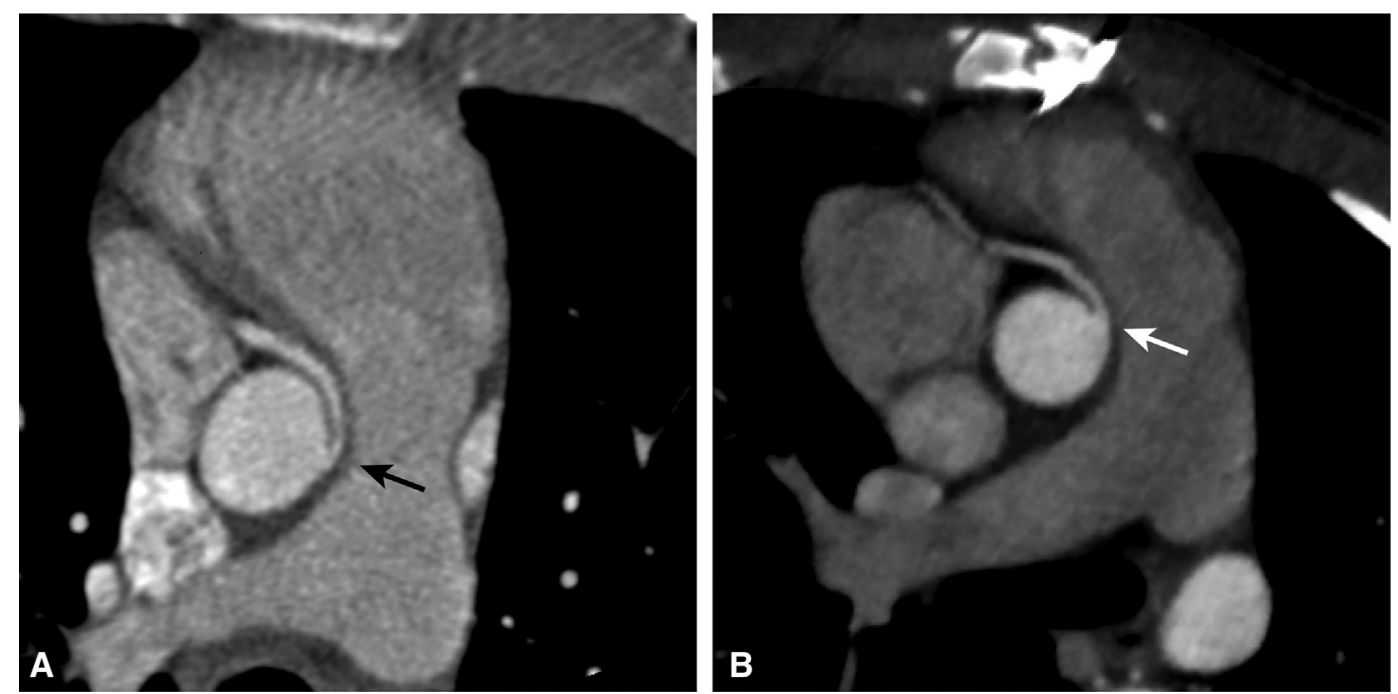

FIGURE 1. Computed tomography showing an anomalous right coronary artery (arrow) with an intramural segment before (A) and after (B) unroofing.

2. Cheezum MK, Liberthson RR, Shah NR, Villines TC, O’Gara PT, Landzberg MJ, et al. Anomalous aortic origin of a coronary artery from the inappropriate sinus of Valsalva. J Am Coll Cardiol. 2017;69:1592-608.

3. Angelini P, Uribe C, Monge J, Tobis JM, Elayda MA, Willerson JT. Origin of the right coronary artery from the opposite sinus of Valsalva in adults: characterization by intravascular ultrasound at baseline and after stent angioplasty. Catheter Cardiovasc Interv. 2015;86:199-208.

4. Sachdeva S, Frommelt MA, Mitchell ME, Tweddell JS, Frommelt PC. Surgical unroofing of intramural anomalous aortic origin of a coronary artery in pediatric patients: single center perspective. J Thorac Cardiovasc Surg. 2018;155:1760-8.
5. Agrawal H, Sexson-Tejtel SK, Qureshi AM, Alam M, Masand P, Fraser CD Jr, et al. Aborted sudden cardiac death after unroofing of anomalous left coronary artery. Ann Thorac Surg. 2017;104:e265-7.

6. Brothers JA, Gaynor JW, Jacobs JP, Poynter JA, Jacobs ML. The Congenital Heart Surgeons' Society Registry of Anomalous Aortic Origin of a Coronary Artery: an update. Cardiol Young. 2015;25:1567-71.

7. Mery CM, Lawrence SM, Krishnamurthy R, Sexson-Tejtel SK Carberry KE, McKenzie ED, et al. Anomalous aortic origin of a coronary artery: toward a standardized approach. Semin Thorac Cardiovasc Surg. 2014;26:110-22. 